\title{
MESSAGE FROM THE EDITOR
}

\section{WE ARE CLICKABLE}

\author{
Pedro Puech-Leão
}

Obviously, good research is unworthy if only the author knows the results. The aim of a scientific journal is to be read.

Medical communication has passed several different phases since Hipocrates started under his famous tree. From oral diffusion till the index medicus, it went through the middle age manuscripts, carefully copied by monks in quiet monasteries, stayed in the famous university libraries in Europe, and got the status of printed media after Gutenberg.

Even after the creation of the Index Medicus, probably the most important contribution of the United States to medical research, communication between scientists in different countries was incomplete. Medical references from South America could be found, but most often the paper itself was not available. The editors of our different publications did their best to send the printed material to every library in the world, but the mission was, indeed, impossible.

The internet, however, has made this possible. Since last April, Revista do Hospital das Clínicas can be read (full-text) in the net, at www.scielo.br/clinicas. Thanks to a well-conducted initiative sponsored by Bireme and FAPESP, the SCIELO PROJECT, all Brazilian journals cited in MEDLINE are online.

But, the most exciting aspect of it is to be linked directly from the NLM site - PubMed. A doctor in Singapore, Philadelphia, Congo or New Zealand, studying a specific topic, can search the literature in PubMed. If he finds an article by a Brazilian researcher, published in our Journal, he can read the abstract. If the abstract shows that the article is worth reading, he clicks on a small frame "transfer to the publisher's site", and...

Articles can be read on the screen, photos can be seen in high resolution and it can be printed in .pdf format, just like it appears in the journal itself. Availability is not a problem anymore. The difference of getting a paper from our journal or from the New England Journal, or Science, or the Lancet, is only a click.

But every conquest carries along a responsibility. The quality of our research is now the only limiting factor in citation. The excuse that our journals were not available will not be valid anymore. If it is good, it shall be read and cited.

The remodeling of Revista do Hospital das Clínicas is complete. It is written in an international language (English), and indexed in MEDLINE (the most used reference source in the world). In the past, our presence in the literature was individual-based. Now, we have to start the journey to our existence, as a community, in the scientific universe. We are more than readable, more than available.

We are clickable. 